\title{
Cost Benefit Analysis of Green Building: A Case Study of Public Office Building in Nepal
}

\author{
Pujan Neupane $^{1^{*}}$, Dalila Afroze ${ }^{2}$, Phonethida Phommasone ${ }^{3}$ \\ ${ }^{1}$ Department of Urban Development and Building Construction, Ministry of Urban Development, Kathmandu, Nepal \\ ${ }^{2}$ Department of Public Health Engineering, Ministry of Local Government, Rural Development and Co-operatives, Dhaka, Bangladesh \\ ${ }^{3}$ Department of Planning and Cooperation, Ministry of Public Works and Transport, Vientiane, Laos
}

DOI: $10.36348 /$ sjet.2020.v05i10.005

| Received: 02.10.2020 | Accepted: 15.10.2020 | Published: 21.10 .2020

*Corresponding author: Pujan Neupane

Email: pujan.neupane@nepal.gov.np

\section{Abstract}

Buildings are the largest consumer of energy and a major source of greenhouse gas (GHG) emission. This incurs a large sum of money to society. It is evident that incorporating green features in buildings can substantially save energy and water consumption, and reduces GHG emissions; however, it is perceived to be costly both by public and private sectors. Often, the investment decisions are made considering the initial cost of the project. Therefore, the purpose of this research is to identify the costs and potential benefits of green buildings over the life cycle of the project using Cost Benefit Analysis (CBA), which performs an economic assessment in project appraisal that helps investors and policymakers in better decision making. The study involves a case study of a public office building from Nepal, which is located at Dumre- Bhansar New Town. The existing building is retrofitted with green components such as solar panels and rainwater harvesting for energy efficiency and water efficiency. The results show that investing in green buildings reduce the life cycle cost of the project, and therefore generates value for money in public investment in the long run. A policy recommendation on subsidy helps in scaling the project to private sectors especially residential buildings. The most important contribution of this study lies in identifying the costs and benefits of green building and introducing the concept of life cycle cost using CBA, which increases awareness and removes barriers in implementing green technologies. This paper also acts as an introductory guideline for project appraisal and formulating policies for the Government of Nepal.

Keywords: Green Building, CBA, life cycle costs, Sustainable Development Goals.

Copyright (C) 2020 The Author(s): This is an open-access article distributed under the terms of the Creative Commons Attribution 4.0 International License (CC BY-NC 4.0) which permits unrestricted use, distribution, and reproduction in any medium for non-commercial use provided the original author and source are credited.

\section{INTRODUCTION \\ Background}

Buildings are one of the main energy users by sector, which is responsible for consuming $73 \%$ of electricity, $40 \%$ of raw materials, $13.6 \%$ of potable water, and $30 \%$ of carbon emissions in the US [1]. The building energy use is projected to be doubled by 2050 , and the greenhouse gas (GHG) emission in this area is projected to reach $14.3 \mathrm{GtCO}_{2} \mathrm{e}$ by 2030 due to population growth, increase in building stock, and lifestyle changes $[7,8]$. This continued rise in energy use is increasing the operating cost of building, for example, the Australian Government annually spends over $\$ 1$ billion on energy and water consumptions [9]. Moreover, the GHG generated from building energy consumption is responsible for an increase in earth temperature, which contributes to disasters linked to climate change. The impact of GHG on society can be monetized that ranges from $\$ 10 / \mathrm{t}$ to $\$ 20 / \mathrm{t}$ of carbon emission [4]. The Paris Agreement of 2015 restates the need to minimize net global emissions close to zero before the end of the century; so, most of the cities are trying to be carbon neutral [11]. To achieve this target, one of the objectives is to promote green building technologies. Green building is a broad concept; however, enhancing energy and water efficiency in both new and existing buildings provides the most diverse, largest, and most cost-effective energy usage and GHG mitigation opportunities. Both the existing and new buildings can be energy efficient by $23 \%$ with the reduction of GHG by $55 \%$ by incorporating green features in the building. by 2030 and 2050, respectively [10]. In monetary terms, this equates to around $\$ 20$ billion in energy savings by 2030 [10]. The average water saving in green buildings is Taiwan was approximately $37.6 \%$ [5]. Over the last three decades, researchers have been demonstrating energy and water savings can be achieved by retrofitting buildings [3], 
Pujan Neupane et al; Saudi J Eng Technol, October, 2020; 5(10): 382-391

and recently it has been observed reductions of 30-40\% is often achievable in buildings [2]. Many studies have been published on CBA of the green building in developed countries [39]; however, this research investigates CBA of the existing public office building by incorporating green features in Nepal. The green building concept is also new to developing countries like Nepal, Bangladesh, and Laos. Therefore, the incorporation of green features in the building sector can make a significant contribution towards achieving the net-zero carbon emission goals as well as can result in significant financial savings globally.

\section{RESEARCH NEEDS}

Public buildings are one of the major sources of energy and water consumption. In China, public buildings comprise $20 \%$ of the total floor areas of the total building stock, but it consumes $31 \%$ of energy and generates $27 \%$ of carbon dioxide emissions [12]. In the context of rising energy and water prices and severe budget constraints, energy and water costs become a major burden to public budgets. To ease these pressures, the public sector needs to cut energy and water costs in the building sector effectively without compromising the comfort of users. In recent years green building technologies have been recognized as the fastest, most cost-effective, and often the easiest path to reduce energy and water use; however, concerns have been raised about the upfront construction cost of green buildings. It is not widely understood that although the initial cost of the green building tends to be higher than conventional buildings, the operational and maintenance costs comparatively low [6]. The U.S. General Services Administration found that green buildings have $19 \%$ lower average maintenance costs, $25 \%$ of lower energy costs, and $34 \%$ lower CO2 emissions [14]. The potential energy and water savings in public buildings could be achieved by installing or retrofitting with green solutions; however, some implementation obstacles hinder even more than in the residential sector. Many home builders, public and private stakeholders, and decision-makers are struggling with the details and concepts of green homes, particularly with the increased initial costs versus the long-term benefits of added green features. The main barrier to the adoption of green buildings is customers' unwillingness to pay additional construction costs. The decisions are often made based on initial project cost rather than considering the operation and maintenance costs, which account for almost $55 \%$ of the total cost, for 40 years in building projects [13]. This inability could impede in formulating effective and efficient policies; therefore, the costs and benefits of green buildings must be clearly illustrated to allow prospective owners to evaluate the option of investing in green buildings with confidence.

\section{RESEARCH AIM AND SCOPE}

Public projects are often implemented for the welfare of society. Public investment in any project is often desirable to deliver benefits and create value for money. There are several ways to access whether the project is profitable; however, CBA is particularly appropriate for a public-funded project [15]. Therefore, this study aims to increase knowledge on the usefulness of CBAs as a basis for project selection since many public and private investors, and government officials lack a proper understanding to develop the costeffectiveness of any intervention. This paper also outlines the concept of green building with its potential costs and benefits. The specific research objectives are as follows:

- To determine the costs and benefits of Green Technology

- To use a CBA as a tool for the feasibility of a project

- To help decision-makers in policy formulation.

The current study is limited to the public building since green building policies targeted at the private sector have little or no credibility unless the government itself is practicing. The energy and water efficiency in public buildings can also have highly visible significant effects throughout the local economy. Moreover, public buildings can also serve as a testbed and training ground to help familiarize contractors, installers, and facility operators with innovative technologies and practices of green building systems. To examine the effectiveness of an intervention, a case study of the government office building is used to illustrate the procedure of cost-benefit analysis. The office building is retrofitted with PV solar panels and rainwater harvesting technology, which can be easily implemented. The result of this research is intended for public and private sector practitioners to conduct an effective, robust economic assessment of not only green buildings but also for other interventions for better decision making for the welfare of society.

\section{LITERATURE REVIEW Green Building}

In recent years there has been considerable growing interest in green buildings, and several studies suggest that green building is efficient in energy consumption, environment friendly and structurally sustainable throughout the building life cycle. The concept of green building was first introduced in 1970 during the energy crisis. Since then, it has been widely applied to achieve a safe and resilient society through optimal utilization of natural resources such as PV solar panels, and rainwater harvesting. The design of a green building is different from a conventional building, and recent research outlines several green technologies can be incorporated in the building. For instance, one of the zero-emission buildings in Korea introduced 95 different green solutions so that the energy consumption is only $1.82 \mathrm{kWh} / \mathrm{m}^{2}$, and the excess energy generated is connected to the national grid [29].

\section{Costs and Benefits of Green Buildings}


A growing body of literature has examined the costs and benefits of green buildings. The costs associated with the green buildings are often the direct costs such as initial cost, operating and maintenance cost, and replacement cost. Several studies [30,31] illustrates the benefits of green buildings in four major categories: economic, social and community, environmental, and government.

Economic aspect: Green buildings have several economic benefits. Firstly, it creates a competitive marketplace for renewable energy, which creates a new job. Secondly, it reduces the life cycle cost of the building, for instance, the installation of the solar panel reduces energy consumption and saves the operating cost remarkably. Thirdly, homeowners capture values from a green building with higher rent and increased productivity with lower medical expenses.

Social and Community aspect: Green building enhances job opportunities for local people thereby reducing unemployment. The experienced employee gets the opportunity for knowledge transfer through training, workshops, which generates additional economic benefits. The green solutions involve the potential for lots of research activities. The results and recommendations of the study increase global networking with the sharing of best practices for the welfare of communities.

Environmental aspect: Environmental aspects are the most widely recognized benefit of green building in reducing the negative externalities in society. Green building reduces $\mathrm{CO}_{2}$ and increases the proper utilization of renewable energy, which is aligned with sustainable development goals.

Government aspect: Since the green building saves costs, increases economic activities, addresses social and environmental issues; thus, from the government perspectives, it helps the government to achieve sustainable development goals.

\section{Barriers in Green Building Implementation}

A significant number of researchers $[32,33,34,37]$ indicates that high initial investment cost and client demand are the key obstacles in implementing green construction. The cost of the green building starts in the design phase. According to Green Building costs (2016), if the green building features are considered in the design stage, it reduces $10 \%$ cost at the construction stage against a 3\% increase in the initial cost [38]. Besides, other researchers [35-37] identify the lack of knowledge and awareness on green construction, and the reluctance of contractor to use new technologies act as a barrier in implementing green building. In summary, the main challenges to implement green buildings are higher initial investment cost, lack of client's interest, knowledge, and awareness on the benefits of green buildings.

To overcome these barriers, the costs and benefits associated with green buildings need to be delineated. Several authors have recommended using cost-benefit analysis as a toolkit to identify and monetize the real costs and the benefits items and to determine the economic feasibility of the project $[15,24,25]$. Until now, in most studies, the cost-benefit analysis of green buildings has only been applied in the context of developed countries, and very few researchers have introduced it to developing countries. In developing countries like Nepal, Bangladesh, and Laos, the characteristics of green technologies are not well understood. The concept of green building is also not widely understood among public officials, policymakers, and decision-makers. Therefore, a number of questions regarding the use of cost-benefit analysis in the project appraisal and the policy formation of the green building remain to be addressed in developing countries.

\section{Principles of Cost-Benefit Analysis}

Cost-Benefit Analysis (CBA) is a toolkit to determine the economic feasibility of an individual project that compares the benefits and costs for the whole society $[16,17]$. CBA provides consistent and objective criteria of project selection from a social welfare point of view. CBA is not about money; it is about welfare. Money is used as an alternative way of measuring welfare. CBA involves evaluating the social value achieved from the project outputs with the value of other goods sacrificed elsewhere for the sake of the project [16]. Conducting a CBA supports the identification of interventions that offer the best value for money and positively contribute to social welfare.

In the CBA social opportunity cost (shadow price) is applied in costing. The producer benefits are measured as producer surplus changes while consumer benefits are measured as consumer surplus changes. The sunk costs are not to be included in CBA since sunk costs are past opportunity costs that are partially or irretrievable and, therefore, should be considered irrelevant to future decision making. Various taxes and simple income transfer for distributional purpose are not included as benefits or costs because it represents transfer payments, which are to be ignored $[17,18]$. All the costs and benefits are aggregated and discounted. Un-monetarized welfares, which do not have market value are to be disclosed. CBA estimates welfare changes of difference between with-the-case and without-the-case scenario, which is a comparison of "with-the-case" and "without-the-case". It is not a comparison of "before" and "after" situation [17]. 
Steps of CBA

\begin{tabular}{|l|r|}
\hline Step-1 & Objective and Scope of the project \\
\hline Step-2 & Cost and Benefit Items \\
\hline Step-3 & Quantification of Cost and Benefit \\
\hline Step-4 & Monetize the impact of the project (Cost and Benefit) \\
\hline Step-5 & I.Aggregate benefits and Costs \\
\hline Step-6 & Calculate NPV, B/C and IRR \\
\hline Step-7 & Sensitivity analysis \\
\hline Step-8 & Interpret Result \\
\hline
\end{tabular}

Fig-1: Steps of Cost Benefit Analysis [2,15,16,17,18]

Step 1: Define the Objective and Scope of the Project: Before evaluating the objective of the project has to be clearly defined. In this stage, the analyst has to examine relevant alternatives to achieve similar results and have to answer whether the proposed intervention is the best way of solving the problem. The analyst should also define the scope of the project.

Step 2: Identify Cost and Benefits Items: The project's direct cost and benefits are identified. Indirect impacts such as social, environmental, and economic should be taken into consideration.

Step 3: Analyse the impacts of the project (Quantification of costs and benefits): CBA estimates welfare changes of difference between with-the-case and without-the-case scenario. It replicates the world without the project and imagines the world with the project. It forecasts the main changes to the counterfactual. Excepted changes are the comparison with the counterfactual. CBA assesses the costs and benefits from a proposed project (intervention) against what would happen otherwise the status quo or baseline, also known as the counterfactual [16]. Converting as many of the costs and benefits into monetary values, including those that are not usually bought or sold under market conditions, allows the analysis to generate a single value such as a social Net Present Value, which estimates whether the proposed project is better for society than the status quo. This approach is generally most useful when most of the impacts identified can be monetized.

Step 4: Monetize the Impacts: A key prerequisite of any CBA modeling is that the costs and benefits associated with any chosen intervention must be easily identifiable and monetized where possible, to maximize the robustness of the analysis undertaken.
Benefits can be measured through individual willingness to pay, sometimes observed. The costs are measured in opportunity cost.

Step 5: Aggregate Benefits and Costs: The benefits and costs project is aggregated to a lifetime. In the time horizon calculated costs and benefits will need to cover the entire economic/functional lifetime of a project. The number of years adopted for this will largely depend on the nature of the intervention being chosen, with benchmarks often varying depending on the sector in question. The time horizon chosen for CBA will play a large role in determining the overall reliability and outcome of model outputs. This is due to the decline in the direct effect of an intervention over time.

Base year: Adopting an appropriate base year for discounting, from which the costs and benefits of alternative interventions will be compared, forms an integral part of any CBA approach.

Choice of social discount rate: An important point to note at this stage is that all future costs associated with intervention will need to be appropriately adjusted. There are two major theories to SDR, which are Social rate of time preference (SRTP) and Marginal Social Opportunity Cost (MSOC) [17,18].

Step 6: Calculate NPV, B/C, and IRR: The criteria for CBA analysis are B/C (Benefit-Cost Ratio), NPV (Net Present Value), and IRR (Internal Rate of Return) $[2,16]$.

Net present value (NPV): The Net Present Value (NPV) discounts all the monetized future costs and benefits, which are anticipated from intervention to their present value or the selected base year. If the NPV 
is positive, the benefits outweigh the costs and generate positive cash flow. If the NPV is negative, the project will never pay back its investment. The higher NPV values assure a greater rate of return on investment. Also, the NPV effectively determines the payback periods associated with an intervention.

Internal rate of return (IRR): The IRR is the discount rate for which the NPV of the project is zero, which represents the rate of return on investments. If the IRR is higher than the rate of return on other alternatives, then the project is economically viable. It can be easily interpretable; however, in the case of more than one alternative, its result can be misleading. For example, a project with a short life cycle might have a high IRR and yield high returns for few years while a project with a lower IRR but with a longer life cycle, might yield higher total investment return over the long term; therefore, it should be used in conjunctions with other parameters.

Benefit-cost ratio (B/C): Benefit-Cost Ratio is one of the primary outputs of CBA that will help to determine the overall cost-effectiveness of an intervention $[2,16]$. It is the ratio of net monetized benefits to net monetized costs for a given base year. The intervention with $\mathrm{B} / \mathrm{C}$ value less than one is an inefficient investment while the $\mathrm{B} / \mathrm{C}$ ratio greater than one represents cost-efficient intervention.

Step 7: Conduct Sensitivity Analysis: It is the technique to determine the robustness of CBA results by accounting for different levels of uncertainties. Sensitivity analysis is performed to determine the overall effect that changes in input data and model assumptions have on CBA outputs [16]. It analyses how sensitive the CBA model is to changes in assumptions of the analysis such as changes in the discount rate, and changes in assumptions on demand.

Step 8: Interpret results and make a decision: The results of CBA are interpreted with the help of standard economic evaluation parameters that help in effective decision making.

\section{METHODOLOGY}

The research is designed to carry out costs and benefits associated with green building. Cost-Benefit Analysis (CBA) is used as a tool to carry out the effectiveness of proposed green building intervention since it has been identified as one of the appropriate methodologies for socioeconomic assessment $[15,24,25]$. To demonstrate the application of CBA in identifying costs and benefits of green building, a case study is carried out in the existing government office building, which is referred to as a "project" in this study. The concept of green building is applied in the integrated office building of the New Town Project Office (NTPO), Dumre-Bhansar, Tanahun, Nepal because this could be a representative of a typical public office building in Nepal. The building has 4 floors with a total floor area of $1,100 \mathrm{~m}^{2}$ and a roof area of floors of $275 \mathrm{~m}^{2}$. The annual power and consumption of the building are $47,872 \mathrm{kWh}$ and 505,450 liters respectively. The data for this study is collected from various sources, which includes some primary data and metadata. The usefulness of the CBA model in evaluating the green building intervention is discussed. Finally, a policy recommendation is done for scaling up it to private sectors.

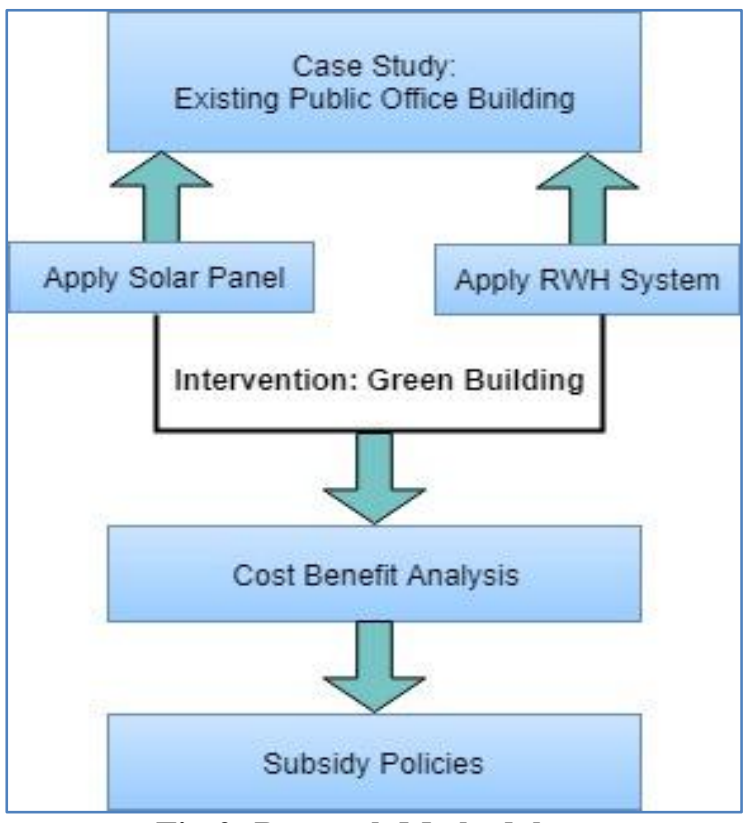

Fig-2: Research Methodology

\section{Cost-Benefit Analysis of Green Building}

The cost-benefit analysis of green building is conducted using the procedure identified in the literature review. The following section describes each stage of the assessment process.

\section{Step 1: Objective and Scope of the Project}

The objective of the project is to reduce the operating costs of public buildings and reduces GHG emissions. The scope of the project is to retrofit the existing building with PV solar panel (Hybrid) on its roof for energy efficiency and to install rainwater harvesting (RWH) technology to improve the water efficiency of the building. In this study, the installation period is considered as one year, and it is assumed that the project will generate cash flow after one year.

\section{Step 2: Cost and Benefit Items}

During an economic appraisal, it is a prerequisite to identify the most significant costs and benefits associated with the project. The costs and benefits items of PV solar panel and rainwater harvesting, identified within the scope of the study, are private cost, which includes capital cost and annual operating and maintenance. The benefits include private benefits and social benefits. 


\section{Capital Cost}

The capital cost is the initial installation cost for a PV solar panel and rainwater harvesting facilities. The office building will be retrofitted with $40 \mathrm{~kW}$ of solar panel and 8 units of rainwater harvesting tank. The installation cost for the PV panel was collected from the Ministry of Physical Infrastructure Development (MPID) of Gandaki Province. The ministry has recently installed a solar system on its roof; so, the installation cost of a solar panel for this study is $\$ 1,728.70 / \mathrm{kW}$, which is the bid price. However, no references have been found on the installation cost of rainwater harvesting in Nepal; so, a detailed cost estimate has been carried out. For this study, \$625.6/unit has been estimated.

\section{Operating \& Maintenance Cost:}

In this study, energy cost and water consumption cost has been considered as the operating cost. The average annual power consumption is calculated in reference to similar government buildings in Kathmandu, Nepal, which is $43.52 \mathrm{kWh} / \mathrm{Sqm}$. The power consumption data of a similar nature of the building is acquired from the Nepal Electricity Authority (NEA), and the details on the total floor area are provided by the Ministry of Urban Development. However, the records for water consumption in public buildings in Nepal were difficult to acquire; so, the rate of annual water consumption is considered as 459.5 liters $/ \mathrm{m}^{2}$ based on the result of other researchers [19]. Other maintenance costs included in the study are annual routine and periodic maintenance that is included in the capital cost. Apart from this, there is also a battery replacement cost for solar panels in every five years.

\section{Benefits}

The benefits considered in this study are power saving from PV solar panels, water-saving for rainwater harvesting, and reduction in $\mathrm{CO}_{2}$ emission. The power generated from a solar panel is calculated in reference to the excepted power output from a solar system installed in MPID. The average annual power output per $\mathrm{kW}$ of PV solar panel is $153.89 \mathrm{kWh}$. The excess energy generated from the system is connected to the grid. The water collected from the rainwater harvesting system is calculated by using the rational method. The runoff coefficient, rainfall intensity, and drainage area are $0.9,90 \mathrm{~mm} / \mathrm{hr}$, and $275 \mathrm{~m}^{2}$.

The annual amount of water harvested is 334,125 liters considering 30 days of rainfall for 5 hours. Since the CBA tool carries project appraisal considering the welfare of the society; therefore, the reduction of $\mathrm{CO}_{2}$ emission due to energy and water saving is considered as a social benefit in this study. The $\mathrm{CO}_{2}$ emission from energy and water consumption is $7.07 * 10^{\wedge}-4$ ton $/ \mathrm{kWh}$ and $0.35 \mathrm{~kg} / 1000$ liters respectively $[20,21]$.

\section{Step 3: Analyse the impacts of the project (costs and benefits)}

The CBA replicates the world without the project and imagines the world with the project. In this case study, CBA evaluates the costs and benefits of a proposed green building retrofitting project (intervention) against what would happen otherwise (the baseline) and estimates whether the proposed project is better than the status quo. Fig 3 shows the world with the green building project and without the green building. The negative value of $\mathrm{CO}_{2}$ indicates a reduction in its emission.

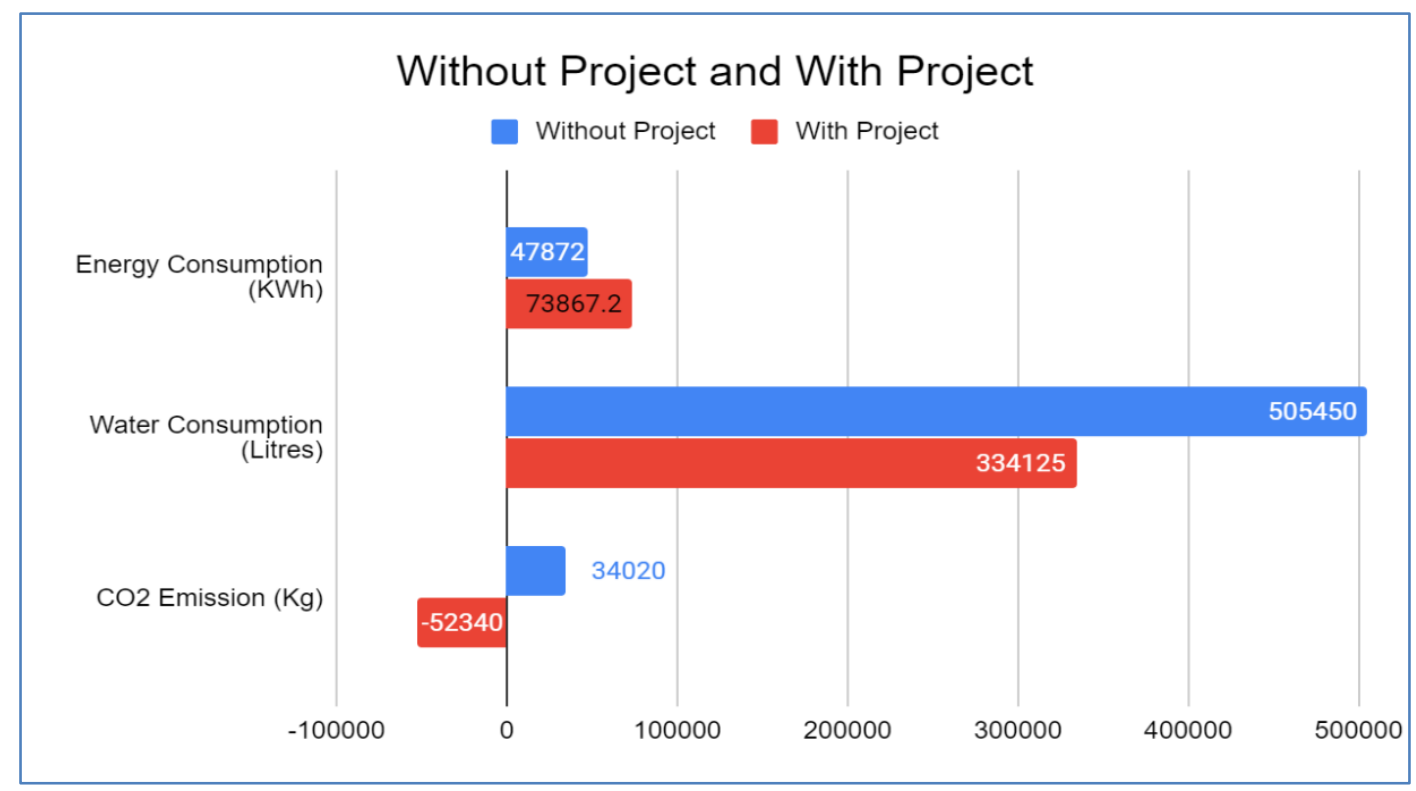

Fig-3: The world With Project vs Without Project 
Pujan Neupane et al; Saudi J Eng Technol, October, 2020; 5(10): 382-391

Step 4: Monetize the Impacts

The costs and benefits of green buildings are monetized with reference to market rate and shadow price collected from various sources as shown in Table 1.

Table-1: Monetization of Costs and Benefits

\begin{tabular}{|l|l|l|}
\hline Cost Item & Value (\$) & References \\
\hline Capital Cost & & \\
\hline Solar PV Panel with Accessories (40 kW) @ 1728.70/kW & 69148 & MPID \\
\hline Rainwater Harvesting (8 Unit) @ 625.6/unit & 5004.8 & Detailed Cost Estimate \\
\hline Operating Cost & & \\
\hline $\begin{array}{l}\text { Annual Energy (Electricity) Consumption (36050 KWh) @ \$ } \\
0.1 / \text { KWh }\end{array}$ & 4787.20 & $\begin{array}{l}\text { Building Inventory \& Tariff Rate of } \\
\text { NEA }\end{array}$ \\
\hline Annual Water Consumption (505450 liters) @ \$0.00054/liter & 274.55 & Local Water Distribution Tariff Rate \\
\hline Battery Replacement every five years (24 Nos) & 4000 & Market Price \\
\hline Benefit Items & & \\
\hline Annual Power Saving (73867.2 KWh) @ \$ 0.1/ KWh & 7386.72 & MPID \& NEA \\
\hline Annual water saving (334125 liters) @ \$0.00054/liter & 181.49 & Rational Equation \& Local Tariff \\
\hline Reduction in $\mathrm{CO}_{2}$ Emission (21.75) @ \$10/ton & 523.40 & World Bank Carbon Pricing \\
\hline
\end{tabular}

\section{Step 5: Aggregate Benefits and Costs}

Since the life of PV solar panel and rainwater harvesting is 20 years, the time horizon for CBA is set at 20 years from the start of the installation. The benefits and costs of the project are aggregated to lifetime for the economic assessment. The base year for discounting is considered as 2020. The social discount rate is calculated from the Social rate of time preference (SRTP) approach since it is suitable for public sectors that have no well-defined market value [22]. The SRTP is calculated as a maximum of Development Bond and Treasury Bill. As per the central bank of Nepal, the interest rate on development bond is $5 \%$ for 15 years and $4.28 \%$ for the treasury bill over 364 days [23]; so, the social discount rate is considered as $5 \%$.

\section{Step 6: Calculate NPV, IRR, and $B / C$ ratio}

The output of CBA is measured against standard parameters: NPV, IRR, and B/C ratio. All the costs including replacement cost and benefits are considered; however, salvage value is ignored since the NPV of salvage value is negligible. The NPV, IRR, and $\mathrm{B} / \mathrm{C}$ ratio of the project are $\$ 14,997.51,7.48 \%$, and 1.252 respectively.

\section{Step 7: Sensitivity Analysis}

Sensitivity Analysis measures uncertainty during project implementation. It measures how the proposed intervention in green technology performs in the long run. Three factors are considered for scenario analysis: SDR, net benefits, and date as follows:

- Social Discount Rate: The effect of SDR on NPV is observed by varying discount rates from $2 \%$ (Low) to $10 \%$ (High).

- Net Benefits: The major benefit item is the power yield from the solar panel. During the analysis, the maximum expected power output was taken to quantify benefit; however, it is sensitive to the weather conditions. So, the monetary value of predicted benefits is varied by $-10 \%,-20 \%$, and, $30 \%$ to study its impact on project feasibility.
- Date (i.e base year) when the green building project is undertaken: The effect on cost and benefits of delaying the investment in green building by 5,10 , 15 , and 20 years is examined.

The project generates positive cash flow until the discount rate is $7.48 \%$. The project generates $\$$ 41801.27 at a discount rate of $2 \%$, and $-\$ 10862.63$ at a discount rate of $10 \%$. So, the discount rate should be cautiously selected to examine the economic viability of the project. As explained above, there are chances of the fluctuation in power output. If the power output decreases by $20 \%$, then the project will not generate positive cash flow; therefore, careful assessment should be conducted for the power generation because it is adversely affecting the project viability. If the commencement of project is deferred by 5 years, 10 years, 15 years, and 20 years, it will impose a financial burden to taxpayers by $\$ 35,032.44\left(\$ 31.84 / \mathrm{m}^{2}\right)$, $\$ 62,481.27\left(\$ 56.80 / \mathrm{m}^{2}\right), \$ 87,695.00\left(\$ 79.72 / \mathrm{m}^{2}\right)$, and $\$ 100,839.35\left(\$ 91.67 / \mathrm{m}^{2}\right)$ respectively.

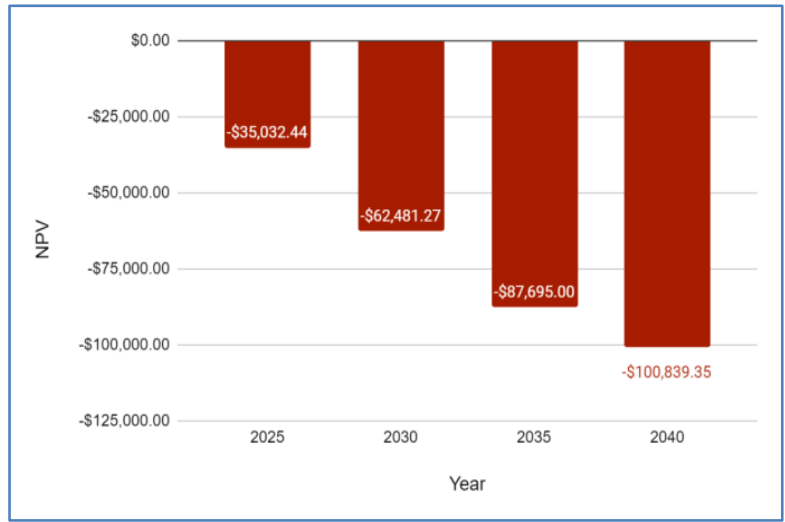

Fig-3: The financial burden on taxpayers from Project Delay

Step 8: Interpret the result and make a decision

Over a period of 20 years, the initial installation cost of solar panels \& rainwater harvesting is $\$ 74,152.80$, which is only a small cost compared to the higher benefit. The NPV of $\$ 14,997.51$, being 
greater than zero, and the IRR $7.48 \%$, which is higher than the discount rate, indicate that the project is economically viable. The payback period is calculated as 11.15 years; hence, solar panel \& rainwater harvesting will be operating as positive cash-generating more years of benefits than years of paying it. These findings are consistent with that of previous studies conducted in the neighboring region $[26,28]$. Thus, the results of the cost-benefit analysis demonstrate the installation of solar panel \& rainwater harvesting as a favorable investment option. By incorporating green features, New Town Project Office will decrease its life cycle cost of building by $\$ 14,997.51$ over a period of 20 years. However, delaying the project adds a financial burden to the government, and the result of sensitivity analysis shows that each year of delay increases the government current expenditure, consequently, budget allocation for capital expenditure will be less. Therefore, the government should not only implement this project by the earliest but also develop a policy framework for scaling it to other buildings including private sectors.

\section{SUBSIDY POLICY}

The CBA shows that green building is beneficial to society, and it generates value for money. Besides, it aligns with sustainable development goals that help to make cities and communities resilient; so, there is a necessity for scaling it to private sectors. The question that needs to be addressed is how much subsidy is needed to make a project viable for the private sector such as a residential building in Nepal. To examine this, the private benefits and social benefits of a green building need to be identified properly. The private benefit considered in this study is energy-saving and water-saving while a reduction in $\mathrm{CO}_{2}$ emission is a social benefit, but the private sector does not account for social benefits in project appraisal. They are more concerned about the Revenue Expenditure (R/E) ratio. The $\mathrm{R} / \mathrm{E}$ value for this project is 0.82 considering the worst-case scenario where the excepted power decreases by $30 \%$. Therefore, the minimum subsidy required to make the project viable is $\$ 12.74 / \mathrm{m}^{2}$ for the private sector. More specifically, the subsidy needed for a solar panel is $\$ 326.16 / \mathrm{kW}$, which is in line with an earlier study in India [26], and the subsidy required for rainwater harvesting is $\$ 3.7 / \mathrm{m}^{2}$.

\section{CONCLUSION}

Green building can save the substantial operating cost of building over the project life cycle; however, it is often criticized for having a high upfront cost compared to a conventional building. The knowledge of costs and benefits of green buildings is also limited among government officials and decisionmakers. Therefore, this study proposes CBA as an assessment tool for project appraisal of green building. The study carried out detailed costs and benefits of green building within its scope. The result of CBA demonstrates green building intervention is feasible and cost-effective for a government office building; however, the benefits should be carefully quantified. This paper has also highlighted that the green building reduces public building operating costs and free up budgets for other uses, and the reduction of GHG emissions helps to mitigate the impacts of climate change. The use of renewable energy also helps the government to align with sustainable development goals no 7,11, and 13, which are renewable energy, sustainable cities and communities, and climate change. However, it is noted that if the government delay implementing green building projects in the public sector, it has to bear the additional cost; therefore, the evidence from this study suggests implementing and upscaling the green building project in the public sector at the earliest so that it will have a more visible impact, and public buildings can lead other building owners. Furthermore, the subsidy framework helps in upscaling the green building concepts in the private sector. It is expected that the result of this study draws the attention of all stakeholders in better decision making. In summary, the CBA provides a proof-of-concept on the usefulness of intervention since it anticipates the world with and without the project and identifies potential costs and benefits along with cost savings and return on investment. The CBA methodology described in this paper also acts as a standard project appraisal guideline for any government intervention.

This study has some limitations. Primarily, the present study considers only PV solar panel and rainwater harvesting; so, future work may consider other green components such as improving building thermal envelope and using water efficiency faucets. Then, the result and conclusion presented are from a case study of one public office building in Nepal. Even though results are promising, it should be validated on a larger scale. Finally, the current work has investigated the power consumption in the low scenario since most of the buildings in Nepal do not have proper heating and cooling system. The authors of this research are public officials from developing countries; so, the authors believe that if a public building has poor heating and cooling facilities, the employees not only feel uncomfortable but also there is a decrease in productivity. Thus, it is also recommended to carry out CBA considering enhanced heating and cooling system in building to boost the productivity of employees in developing countries.

\section{ACKNOWLEDGMENTS}

This study is developed from the group project work in the class of Public Investment Management, Fall 2019; so, we thank Prof. Dr. Hyeon Park, Dean of International School of Urban Sciences, the University of Seoul for his valuable guidance. 
Pujan Neupane et al; Saudi J Eng Technol, October, 2020; 5(10): 382-391

\section{REFERENCES}

1. Council, U. G. B. (2015). Green building facts.

2. Bertone, E., Sahin, O., Stewart, R. A., Zou, P., Alam, M., \& Blair, E. (2016). State-of-the-art review revealing a roadmap for public building water and energy efficiency retrofit projects. International Journal of Sustainable Built Environment, 5(2), 526-548. DOI: https://doi.org/10.1016/j.ijsbe.2016.09.004

3. Goldman, C. A., Greely, K. M., \& Harris, J. P. (1988). Retrofit experience in US multifamily buildings: Energy savings, costs, and economics. Energy, 13(11), 797-811. DOI: https://doi.org/10.1016/0360-5442(88)90085-0

4. Ramstein, C., Dominioni, G., Ettehad, S., Lam, L., Quant, M., Zhang, J., ... \& Merusi, C. (2019). State and trends of carbon pricing 2019. The World Bank. DOI: https://doi.org/10.1596/978-1-46481435-8

5. Sun, C. Y., Chen, Y. G., Wang, R. J., Lo, S. C., Yau, J. T., \& Wu, Y. W. (2019). Construction cost of green building certified residence: A case study in Taiwan. Sustainability, 11(8), 2195. DOI: https://doi.org/10.3390/su11082195

6. Weerasinghe, A. S., \& Ramachandra, T. (2018). Economic sustainability of green buildings: a comparative analysis of green vs non-green. Built Environment Project and Asset Management. DOI: https://doi.org/10.1108/BEPAM-10-2017-0105

7. Alam, M., Zou, P. X., Stewart, R. A., Bertone, E., Sahin, O., Buntine, C., \& Marshall, C. (2019). Government championed strategies to overcome the barriers to public building energy efficiency retrofit projects. Sustainable Cities and Society, 44, 56-69.

DOI: https://doi.org/10.1016/j.scs.2018.09.022

8. Zou, P. X., Alam, M., \& Hebert, L. (2019). Closing the gap between design and reality of building energy performance. Website: www.sbenrc.com.au

9. Zou, P. X., Alam, M., Phung, V. M., Wagle, D., Stewart, R. A., Bertone, E., ... \& Buntine, C. (2017). Achieving energy efficiency in government buildings through mandatory policy and program enforcement. Frontiers of Engineering Management, 4(1), 92-103. DOI: 10.15302/J-FEM2017101

10. ASBEC, L. C. (2016). High Performance: How buildings can make a major contribution to Australia's emissions and productivity goals, in. Australian Sustainable Built Environment Council.

11. Agreement, P. (2015). Paris agreement. In Report of the Conference of the Parties to the United Nations Framework Convention on Climate Change (21st Session, 2015: Paris). Retrived December (Vol. 4, p. 2017).

12. Xie, B. C., Zhai, J. X., Sun, P. C., \& Ma, J. J. (2020). Assessment of energy and emission performance of a green scientific research building in Beijing, China. Energy and Buildings, 224,
110248.

DOI:

https://doi.org/10.1016/j.enbuild.2020.110248

13. Flanagan, R., Norman, G., \& Meadows, J. (1989). Life cycle costing: theory and practice. BSP Professional Books.

14. Fowler, K. M., Rauch, E. M., Henderson, J. W., \& Kora, A. R. (2010). Re-assessing green building performance: A post occupancy evaluation of 22 GSA buildings (No. PNNL-19369). Pacific Northwest National Lab.(PNNL), Richland, WA (United States). DOI: 10.2172/1029438

15. Boardman, A. E., Greenberg, D. H., Vining, A. R., \& Weimer, D. L. (2017). Cost-benefit analysis: concepts and practice. Cambridge University Press.

16. Thomson, C., Franklin, R., \& Groth , D. (2019). Guidance on project level socio-economic assessment. Edinburgh: The Scottish Government. Retrieved April 12, 2020, from www.gov.scot

17. De Rus, G. (2010). Introduction to cost-benefit analysis: looking for reasonable shortcuts. Edward Elgar Publishing.

18. Boardman, A. E., Greenberg, D. H., Vining, A. R., \& Weimer, D. L. (2017). Cost-benefit analysis: concepts and practice. Cambridge University Press.

19. Tabassum, R., Arsalan, M. H., \& Imam, N. Estimation of Water Demand For Commercial Units in Karachi City.

20. EPA. (2020). Greenhouse Gases Equivalencies Calculator - Calculations and References. Retrieved April 12, 2020, from https://www.epa.gov/energy/greenhouse-gasesequivalencies-calculator-calculations-andreferences

21. Carbon Neutral Charitable Fund. (2020). My Carbon Calculator. Retrieved April 12, 2020, from https://cncf.com.au/

22. Spackman, M. (2004). Time discounting and of the cost of capital in government. Fiscal Studies, 25(4), 467-518. DOI: https://doi.org/10.1111/j.14755890.2004.tb00547.x

23. Central Bank of Nepal. (2019). Interest Rate. Retrieved December 01, 2019, from https://www.nrb.org.np/

24. Volden, G. H. (2019). Assessing public projects' value for money: An empirical study of the usefulness of cost-benefit analyses in decisionmaking. International Journal of Project Management, 37(4), 549-564.

25. Sofia, D., Gioiella, F., Lotrecchiano, N., \& Giuliano, A. (2020). Cost-benefit analysis to support decarbonization scenario for 2030: A case study in Italy. Energy Policy, 137, 111137.

26. Wampler, M. A. (2011). Cost-Benefit Analysis of Installing Solar Panels on the Schnoor Almond Ranch. Website: https://digitalcommons.calpoly.edu/agbsp/59

27. Tarai, R. K., \& Kale, P. (2018). Solar PV policy framework of Indian States: Overview, pitfalls, challenges, and improvements. Renewable Energy Focus, 26, 46-57. 
28. Nawaraj, S., Malesh, S., Alex, Z., \& Muniraj, U. (2009). Power Generation Potential and Cost of a Roof Top Solar PV System in Kathmandu, Nepal. In National Conference RETSUD.

29. Schuetze, T., \& Hagen Hodgson, P. (2014). Zero Emission Buildings in Korea. Website: http://www.sciforum.net/conference/wsf-4

30. Shabrin, N., \& Kashem, S. B. (2017). A comprehensive cost benefit analysis of green building. In Proceedings of 94th IIER International Conference.

31. Garcia, A. J., Mollaoglu, S., \& Syal, M. (2017). NGBS-Certified Single-Family Green Homes: Costs and Benefits. Practice Periodical on Structural Design and Construction, 22(3), 05017001.

32. Kibert, C. J. (2016). Sustainable construction: green building design and delivery. John Wiley \& Sons.

33. Bond, S., \& Perrett, G. (2012). The key drivers and barriers to the sustainable development of commercial property in New Zealand. Journal of sustainable real estate, 4(1), 48-77.

34. Hwang, B. G., \& Tan, J. S. (2012). Sustainable project management for green construction: challenges, impact and solutions. In World construction conference (pp. 171-9).

35. Hwang, B. G., \& Tan, J. S. (2012). Green building project management: obstacles and solutions for sustainable development. Sustainable development, 20(5), 335-349.

36. Simpeh, E. K., \& Smallwood, J. J. (2015). Factors influencing the growth of green building in the South African construction industry. In Smart and Sustainable Built Environment (SASBE) Conference 2015 (p. 311).

37. Firdaus, A., Setiawan, T. H., \& Reynaldy, J. I. (2018). Barriers to the implementation of green construction: a case study in Bandung, Indonesia. International Journal of Integrated Engineering, 10(8).

38. Green, Building Costs. (2016). The city of Bloomington. Retrieved February 6, 2016, from https://bloomington.in.gov/green-building-costs

39. KO, Minhyok. (2019). Green Building in Cambodia (Unpublished Global Network Seminar Report submitted to Professor SHIN LEE). The University of Seoul, Seoul, South Korea. 